\title{
Presbyopic Spectacle Coverage, Willingness to Pay for Near Correction, and the Impact of Correcting Uncorrected Presbyopia in Adults in Zanzibar, East Africa
}

\author{
Heidi R. Laviers, ${ }^{1}$ Fatma Omar, ${ }^{2}$ Hakika Jecha,${ }^{2}$ Garnia Kassim, ${ }^{2}$ and Clare Gilbert ${ }^{1}$
}

Purpose. To assess presbyopic spectacle coverage, willingness to pay, and the impact of correcting uncorrected presbyopia in individuals 40 years of age and older in Zanzibar and whether assessment of presbyopia can be incorporated into Rapid Assessment of Blindness (RAAB) surveys.

Methods. A cross-sectional, population-based survey of presbyopia was incorporated into a RAAB survey. The sample size of 400 included individuals older than 50 years (from RAAB survey) and those 40 to 50 years old (from the same household) who had a corrected visual acuity (VA) of at least $6 / 18$ in either eye. An Ophthalmic Clinical Officer (OCO) administered visual function (VF) and quality of life (QOL) questionnaires followed by clinical assessment by an optometrist. Participants requiring a simple near addition were dispensed free readymade spectacles. The same team traced participants 6 months later and readministered the questionnaires. Those requiring new spectacles had their near VA measured and were given spectacles.

Results. Three hundred eighty-one participants were examined. The prevalence of presbyopia was $89.2 \%(340 / 381)$ and spectacle coverage was only $17.6 \%$. Barriers to accessing services included spectacles not being a priority and lack of money. At follow-up, 175 (93.6\%) of 187 participants given spectacles still had them. Mean satisfaction was high at $89.5 \%$. The mean amount participants were willing to pay for spectacles had increased from 2.17 USD at baseline to 3.14 USD at follow-up. The impact of correcting presbyopia on VF produced an effect size of 2.90 and effect sizes ranging from 1.15 to 3.90 for mean QoL scores.

ConcLusions. This study highlights the value of correcting presbyopia from the community perspective and the necessity of providing affordable, quality, and accessible near spectacles at the primary health level. (Invest Ophthalmol Vis Sci. 2010;51: 1234-1241) DOI:10.1167/iovs.08-3154

$\mathrm{T}$ he World Health Organization (WHO) estimated in 2002 that approximately 37 million people worldwide were blind and 124 million were visually impaired. ${ }^{1}$ A further 153

From the ${ }^{1}$ International Centre for Eye Health, London School of Hygiene and Tropical Medicine, London, United Kingdom; and the ${ }^{2}$ Mnazi Mmoja Hospital, Stonetown, Zanzibar, East Africa.

Supported by International Centre for Eye Health, Sightsavers International, Mnazi Mmoja Hospital, and the Zanzibar Ministry of Health.

Submitted for publication, November 13, 2008; revised April 23 and June 11 and 24, 2009; accepted July 6, 2009.

Disclosure: H.R. Laviers, None; F. Omar, None; H. Jecha, None; G. Kassim, None; C. Gilbert, None

Corresponding author: Heidi R. Laviers, 26 Danbury Street, London N1 8JU, UK; laviers@hotmail.com. million people are visually impaired from uncorrected refractive errors, 8 million of whom are blind. ${ }^{2}$ Refractive errors can be managed with the simple, highly cost-effective intervention of optical correction, and provision of services for refractive error is a priority of VISION2020: the Right to Sight. However, global estimates of the number of people with uncorrected presbyopia are very limited. ${ }^{3}$ It was estimated that 1.04 billion people were presbyopic, 517 million of whom were without adequate correction in $2005 .{ }^{4}$ The magnitude and need for spectacle correction for near vision will increase as the world's population increases, ages, and becomes more literate. Variability in the onset and degree of presbyopia can depend on climate, geographic location, sex, and ethnicity. However, studies have not always adequately adjusted for confounding. ${ }^{4-7}$

In terms of priority setting for provision of services for presbyopia, WHO has recommended if less than one third of those affected have near correction, the population would be ranked as a high priority for service delivery. If one to two thirds have spectacles, the priority ranking would be moderate, and if more than two thirds have spectacles, it would be low.

Since most optical suppliers and hospitals provide spectacles at relatively high prices, alternative approaches are needed. Popular strategies to improve presbyopic spectacle coverage include community distribution schemes; for example, the use of trained "village entrepreneurs," a model being used by the ScoJo Foundation, $, 9,10$ or "vision guardians," used by the vision centers in India. ${ }^{11}$ The scheme links up with existing local networks of health workers or village distributors and is sustainable due to its basis of community participation and each level being profitable. ${ }^{10}$

The two islands of Zanzibar, Unguja and Pemba, are situated off the east coast of Africa, and form part of the United Republic of Tanzania and Zanzibar. Zanzibar has a population of approximately 1 million. There are 142 primary health care units (PHCUs) and 4 primary health care centers (PHCCs) distributed over the two islands, within a few kilometers of most of the population.

The purpose of the study was to estimate spectacle coverage for presbyopia in adults 40 years of age and older in Zanzibar, barriers to accessing services, and the amount individuals would be willing to pay for presbyopic correction and whether they would be willing to participate in a community distribution scheme. A questionnaire was used to assess visual function (VF), quality of life (QoL) and satisfaction at baseline, and attempts were made to trace all those given or prescribed presbyopic spectacles and assess their satisfaction 6 months later. The study was undertaken as part of a Rapid Assessment of Avoidable Blindness (RAAB) survey to ascertain the feasibility of adding assessment of presbyopia to this methodology. ${ }^{12,13}$ 


\section{Methods}

\section{Baseline}

The following were used to calculate the sample size for the prevalence survey: estimated prevalence of $61.7 \%$ among individuals aged $\geq 40$ years and precision of the $5 \%$ and $95 \%$ confidence level. ${ }^{7,14}$ The sample size was calculated to be 400 , which included an additional $10 \%$ to allow for nonresponse. The sample size for the RAAB survey was 3300 .

Using the 2002 population census, a nationally representative sample of adults $>50$ years of age was recruited for the RAAB survey by using multistage, cluster random sampling with probability proportionate to size procedures. ${ }^{12,13}$ In each cluster, compact segment sampling was used with door-to-door enumeration. For the RAAB survey 66 clusters were selected, and each cluster included 50 individuals older than 50 years. For the study of presbyopia 16 of the 66 clusters were randomly selected by systematic random sampling and each cluster included 25 of the 50 enumerated individuals (i.e., 400 individuals aged above 50 years). Individuals aged 40 to 50 years who lived in enumerated households were also invited to take part in the study of presbyopia.

All enumerated individuals had their presenting distance visual acuity (VA) measured in each eye using a Snellen $\mathrm{E}$ chart at $6 \mathrm{~m}$ at their household. Those with a presenting VA of $<6 / 18$ in one or both eyes had VA retested with a pinhole test. Individuals older than 40 who had a presenting or corrected distance VA of $6 / 18$ or better in one or both eyes were recruited to the presbyopia study.

The definition of presbyopia used the near equivalent of distance visual impairment (VI) (i.e., <6/18) which translates to N8-sized print at $40 \mathrm{~cm}$ with a logMAR tumbling $\mathrm{E}$ chart, requiring at least $+1.00 \mathrm{D}$ near add to see clearly. WHO definitions of refractive error were used: myopia, $\leq-0.50 \mathrm{D}$; hypermetropia, $\geq+2.00 \mathrm{D}$; astigmatism, $\geq 2.00 \mathrm{D}$; and anisometropia, $\geq 2.00 \mathrm{D}^{8}{ }^{8} \mathrm{WHO}$ categories of VI were also used that rely on the presenting VA of the better seeing eye (i.e., not impaired, $6 / 18$ or better; mild VI, $<6 / 18-6 / 60$; severe VI, $<6 / 60-3 /$ 60 ; and blind, $<3 / 60)^{2}{ }^{2}$ Spectacle coverage (\%) was determined using the formula: met need/(met need + unmet need) $\times 100$, where met need is the number of presbyopic participants who already had spectacles, and unmet need is the number who did not. ${ }^{15}$ Literacy was defined as the ability to read and/or write.

The same team members were used for both the baseline and follow-up studies and consisted of an optometrist, an Ophthalmic Clinical Officer (OCO), a RAAB team member, and the team leader (HL, an optometrist). The instruments used to assess VF and vision-related QOL at baseline and again at 6 months were adapted from instruments used in studies in India and Tanzania. ${ }^{6,7,14}$ The instruments were translated into Swahili and then back translated by another person into English to check accuracy. The questionnaire was pretested on 30 individuals, and measures of interobserver agreement between the optometrists were performed on their clinical findings with interviewer assessment included.

The presbyopia study team accompanied one of the three RAAB teams to enumerated villages. A temporary clinic was set up at a local meeting point with access to a dark room. Participants were recruited from the RAAB survey where the OCO measured distance VA with and without a pinhole, monocularly and binocularly, using a logMAR E chart in outdoor ambient lighting outside the participant's house.

Clinical examination at the temporary clinic included ophthalmoscopy, retinoscopic refraction, and measurement of best corrected distance VA. Near VA was assessed by the ability to read N8 at $40 \mathrm{~cm}$ on a $\operatorname{logMAR} \mathrm{E}$ chart, with and without distance correction under standard lighting conditions (at least 480 lux by light meter). ${ }^{16}$ The least binocular add required for participants to see $\mathrm{N} 8$ clearly at $40 \mathrm{~cm}$ was assessed by adding increments of $+0.25 \mathrm{D}$. The near add required using participant's habitual working distance (i.e., the distance participants chose) was also recorded. Ready-made near spectacles assessed using habitual working distance were provided free by the International Centre for Eye Education,
Durban, South Africa. Participants with significant refractive errors were given their prescription, referred to a local eye clinic, and supplied with spectacles at a charge. Those with reduced corrected distance VA were referred for further ophthalmic assessment. Further interviews were performed, where applicable, by the OCO regarding VF, QoL, barriers to the uptake of services, and willingness to pay for spectacles and to seek the participants' views on a community distribution scheme for spectacles. In relation to willingness to pay, participants were asked how much they would pay for a pair of spectacles in Tanzanian shillings (TSh), and to indicate what proportion of the monthly family income this represented. Financial questions were asked in private.

\section{Follow-up}

At the 6-month follow-up, village chiefs in the 16 study clusters were informed that the team would revisit the village 2 days hence and provide a list of individuals to be traced in their village. A temporary station was set up and those who did not attend were visited at home. The questionnaire was administered, and the simple task of threading a needle with and without near spectacles was performed. Those requiring new spectacles had their near VA rechecked and were given a replacement pair of spectacles.

VF questions related to near visual tasks, with near glasses if applicable. Participants were asked to grade near visual tasks (e.g., threading a needle, lighting a lamp, and seeing mobile phone numbers) with a level of difficulty ranging from very difficult to very easy on a subscale of 1 to 5. QoL questions involved similar individual subscales but rated their level of satisfaction with more general aspects of life. Participants were asked if they would recommend spectacles to those with near vision difficulties and to rate their level of satisfaction with their spectacles on a similar subscale.

Before the study team started their field work, a 1-day period of training was conducted that included recruitment protocols and interview procedures, consistency checks, and pretesting of the questionnaire and interobserver agreement.

The protocol was approved by the London School of Hygiene and Tropical Medicine ethics committee and the Zanzibar Ministry of Health and adhered to the tenets of the Declaration of Helsinki. All participants gave written informed consent and those requiring treatment were treated or referred accordingly.

\section{Data Management}

Data were entered into a database made in Epi info (http://www. cdc.gov/epiinfo/ provided in the public domain by the Centers for Disease Control, Atlanta Georgia) and statistical analyses were performed (STATA 9 and SPSS software packages, SPSS, Chicago, IL).

Data were collected and analyzed for both eyes. Where appropriate (e.g., VA assessment) binocular findings were used in the analyses. Refractive errors were converted to spherical equivalents (SphEq). An individual was defined as being potentially able to benefit from readymade spectacles if he or she had $<2 \mathrm{D}$ of cylinder in both eyes and $<2$ $\mathrm{D}$ difference in SphEq between eyes. Most analyses were performed with the Pearson $\chi^{2}$ test used to determine associations. Only those variables showing significant associations $(P<0.1)$ on univariate analysis were included in the multivariate models.

The follow-up analysis included only the presbyopic participants traced with an unmet need at baseline who were either given spectacles or purchased spectacles (176 participants; Fig. 1).

The VF data were analyzed by summing scores for each question and producing a total score that was linearly transformed to give a score out of $100 .{ }^{17,18}$ Higher scores represented better levels of functioning. VF scores were normally distributed at baseline. Univariate and multivariate linear regressions were used to assess associations between mean total scores and baseline characteristics and clinical measures. Cronbach coefficient $\alpha$ was used as a method of internal consistency and reliability assessment of the questionnaires (Cronbach coefficient $\alpha \mathrm{VF}=0.8$ ). 


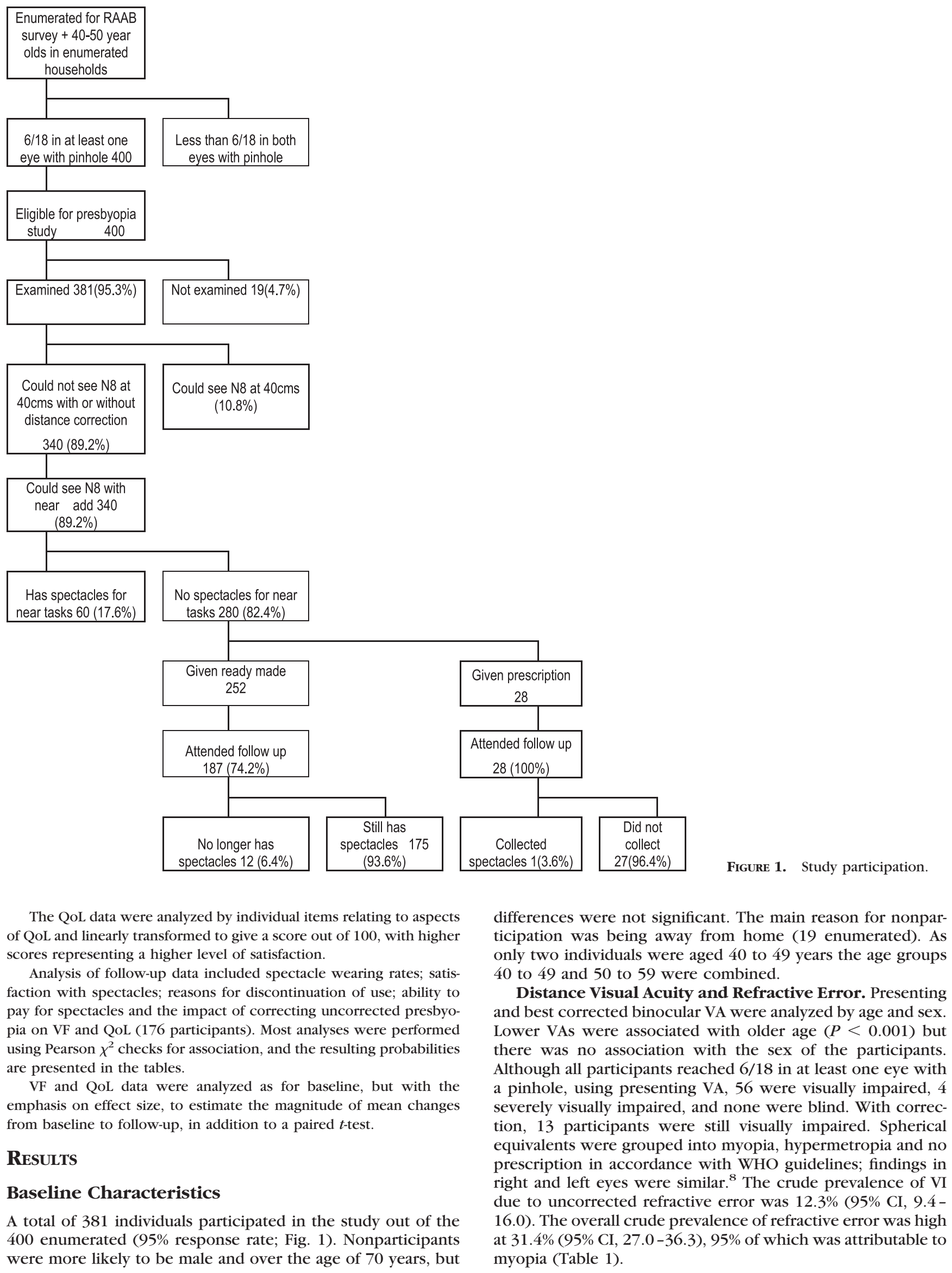


TABLE 1. Spherical Equivalents for Right and Left Eyes According to Age and Sex

\begin{tabular}{|c|c|c|c|c|c|c|c|c|c|}
\hline \multirow[b]{2}{*}{ Characteristic } & \multicolumn{2}{|c|}{ Myopia } & \multicolumn{2}{|c|}{ Emmetropia } & \multicolumn{2}{|c|}{ Hypermetropia } & \multicolumn{2}{|c|}{ Total } & \multirow[b]{2}{*}{$\boldsymbol{P}$} \\
\hline & $n$ & $\%$ & $n$ & $\%$ & $n$ & $\%$ & $n$ & $\%$ & \\
\hline \multicolumn{10}{|l|}{ Right Eye } \\
\hline \multicolumn{10}{|l|}{ Age (y) } \\
\hline $40-59$ & 65 & 26.6 & 177 & 72.5 & 2 & 0.8 & 244 & 100.0 & \\
\hline $60-69$ & 32 & 31.4 & 67 & 65.7 & 3 & 2.9 & 102 & 100.0 & \\
\hline $70+$ & 14 & 40.0 & 21 & 60.0 & 0 & 0.0 & 35 & 100.0 & 0.193 \\
\hline \multicolumn{10}{|l|}{ Sex } \\
\hline Male & 52 & 33.5 & 101 & 65.2 & 2 & 1.3 & 155 & 100.0 & \\
\hline Female & 59 & 26.1 & 164 & 72.6 & 3 & 1.3 & 226 & 100.0 & 0.290 \\
\hline \multicolumn{10}{|l|}{ Left eye } \\
\hline \multicolumn{10}{|l|}{ Age (y) } \\
\hline $40-59$ & 68 & 27.9 & 174 & 71.3 & 2 & 0.8 & 244 & 100.0 & \\
\hline $60-69$ & 33 & 32.4 & 66 & 64.7 & 3 & 2.9 & 102 & 100.0 & \\
\hline $70+$ & 14 & 40.0 & 21 & 60.0 & 0 & 0.0 & 35 & 100.0 & 0.236 \\
\hline \multicolumn{10}{|l|}{ Sex } \\
\hline Male & 57 & 36.8 & 96 & 61.9 & 2 & 1.3 & 155 & 100.0 & \\
\hline Female & 58 & 25.7 & 165 & 73.0 & 3 & 1.3 & 226 & 100.0 & 0.067 \\
\hline
\end{tabular}

Prevalence of Presbyopia. The crude prevalence of presbyopia (WHO proposed definition) was high at $89.2 \%$ (95\% CI, 85.7-92.0) and there were no significant differences by age group, sex, dwelling, or literacy.

Near Add Required. Correcting distance VA had little impact on near acuity, but with a near add, the proportion of individuals who could see N8 increased from 10.2\% (95\% CI, 7.6-13.7) at presentation to $98.2 \%$ (95\% CI, 96.2-99.2; Table 2). The mean near add required for participants to see N8 clearly at a comfortable working distance was $2.2 \mathrm{D}$ (range, 1.50-3.00 D), significantly higher than the mean near add required of $1.64 \mathrm{D}$ (range, $1.00-2.50 \mathrm{~s}$ ) for participants to read $\mathrm{N} 8$ at $40 \mathrm{~cm}$ (Table 3). The need for near spectacle correction could be met by readymade spectacles in $89.2 \%$ of individuals.

Met Need and Spectacle Coverage. Among the 381 individuals examined, 340 needed spectacles for presbyopia, but only 60 had them (coverage, 17.6\%; 95\% CI, 14.0-22.1). In univariate analysis, urban location, higher education, and certain occupations were significantly associated with met need. Multivariate analysis showed that being educated to the secondary level (OR 2.6; 95\% CI, 1.4-6.7, $P=0.005$ ) or higher (OR 4.3; 95\% CI, 2.1-13.2, $P<0.001$ ) remained independently associated with owning presbyopic correction (Table 4).

Barriers to Uptake of Services. Two hundred eighty participants were interviewed concerning why they did not own presbyopic spectacles. The commonest reasons cited were that spectacles were not regarded as a high priority (33\%; $95 \%$ CI, 28.1-38.7), lack of money (30.6\%; 95\% CI, 25.6-36), and lack of awareness that their near vision could be improved
(14.6\%; 95\% CI, 11.1-19.1). There were no sex or age group differences.

\section{Results at Follow-up}

At follow-up, all 28 given a prescription and 187 of those given ready-made spectacles were re-examined (total $=215 / 280$, $76.8 \%$; Fig. 1). Reasons for loss to follow-up among the 65 presbyopic individuals who did not attend were: moved away (12.9\%), died (2.4\%), or could not be traced (84.7\%). The age, sex, and rural/urban characteristics of participants and nonparticipants were similar.

Among the 215 presbyopes re-examined at follow-up, 176 still had a presbyopic correction and had VF and QoL data at baseline and at follow-up.

Spectacle Status and Barriers to Service. Of the 187 participants given a near add, 175 still had their spectacles at follow-up (93.6\%; 95\% CI, 89.1-96.6) whereas only 1 (3.6\%) of 28 of those given a prescription had collected their spectacles (Fig. 1). Only $1.1 \%$ could thread a needle without their near add compared with $95.5 \%$ when wearing their spectacles.

The main reasons for no longer having spectacles were that they were broken $(41.7 \%$; $95 \%$ CI, $15.2-72.3)$ or lost $(41.7 \%$; 95\% CI, 15.2-72.3). Spectacles were not replaced on account of cost $(54.6 \%$; 95\% CI, 14.2-61.7) and distance $(27.3 \%$; $95 \%$ CI, 0.1-53.6). Cost was also the main reason why participants given a prescription had not collected their spectacles $(29.6 \%$; 95\% CI, 13.8-50.2).

Use of Spectacles and Satisfaction. Only one participant had never worn the spectacles and three reported constant

TABle 2. Assessment of Near Vision (Can See N8 at $40 \mathrm{~cm}$ ) by Age and Sex

\begin{tabular}{|c|c|c|c|c|c|c|c|c|c|}
\hline \multirow[b]{2}{*}{ Variable } & \multicolumn{3}{|c|}{ At Presentation } & \multicolumn{3}{|c|}{ With Distance Correction } & \multicolumn{3}{|c|}{ With Near Addition } \\
\hline & $n$ & $\%$ & $\boldsymbol{P}$ & $\boldsymbol{n}$ & $\%$ & $\boldsymbol{P}$ & $n$ & $\%$ & $\boldsymbol{P}$ \\
\hline \multicolumn{10}{|l|}{ Age (y) } \\
\hline $40-59$ & 27 & 11.1 & & 31 & 12.7 & & 240 & 98.4 & \\
\hline $60-69$ & 6 & 5.9 & & 8 & 7.8 & & 99 & 97.1 & \\
\hline $70+$ & 6 & 17.1 & 0.13 & 2 & 5.7 & 0.25 & 35 & 100.0 & 0.5 \\
\hline \multicolumn{10}{|l|}{ Sex } \\
\hline Male & 52 & 33.5 & & 57 & 36.8 & & 151 & 97.4 & \\
\hline Female & 59 & 26.1 & & 58 & 25.7 & & 223 & 98.7 & \\
\hline Total & 39 & 10.2 & $<0.001$ & 41 & 10.8 & $<0.001$ & 374 & 98.2 & 0.37 \\
\hline
\end{tabular}


Table 3. The Mean Add Needed to Read N8 at $40 \mathrm{~cm}$ Compared with the Add Needed for Habitual Working Distance

\begin{tabular}{ccccc}
\hline $\begin{array}{c}\text { Age Group } \\
\text { (y) }\end{array}$ & $\begin{array}{c}\text { Mean Add Needed } \\
\text { for } \mathbf{4 0} \mathbf{~ c m}^{*} \text { (D) }\end{array}$ & Significance & $\begin{array}{c}\text { Mean Add Needed } \\
\text { Habitual (D) }\end{array}$ & Significance \\
\hline $40-59$ & 1.16 & $F=52.8$ & 1.89 & $F=47.6$ \\
$60-69$ & 1.74 & $2 d f$ & 2.30 & $2 d f$ \\
$70+$ & 2.01 & $P<0.001$ & 2.46 & $P<0.001$ \\
\hline
\end{tabular}

* Currently proposed definition.

use. Almost half said they used their spectacles daily. Participants were generally satisfied with their spectacles, with urban men being the most satisfied subgroup (mean scores, 91.1 and 89.3 , respectively). A very high proportion of participants said they would recommend near correction to others $(86.9 \%$; $95 \%$ CI, 81.0-91.5).

Visual Function at Baseline and Follow-up. At baseline, 99.4\% of participants required help for near activities. Mean VF scores were analyzed according to baseline characteristics and clinical measures. The overall mean VF score was 64.4. Rural dwellers had a significantly lower mean VF scores than did urban dwellers (62.42 and 66.65, respectively, $P<0.001$ ), as did illiterate participants compared to literate participants (63.31 and 70.39, respectively, $P<0.001$ ). Only literacy remained significant in the multivariate analysis. Illiteracy was associated with lower VF scores with an adjusted coefficient of 4.67 (95\% CI, -8.36 to $-0.99 ; P=0.013$ ). No association was found between the degree of near add required and VF (test for trend, $P=0.418)$. At 6 months follow-up, $85.8 \%$ of participants (151/176; 95\% CI, 80.0-90.6) no longer required help from others for near tasks, and the overall mean VF score increased to 91.5 . The effect size was very high (2.90), and the paired $t$-test showed a significant difference in mean scores between baseline and follow-up ( $P<0.001$; Table 5$)$. Near spectacles had the most impact on reading small print and threading a needle, with effect sizes of 3.8 and 2.7, respectively.

QoL at Baseline and Follow-up. Mean QoL scores were calculated at baseline for each item (Table 6). Near vision produced the lowest mean score of 44.9 (95\% CI, 43.2-46.7) and family relations was considered the highest with a mean score of $82.0 \%$ (95\% CI, 81.1-83.2). At 6 months the mean QoL score had improved particularly for near vision (effect sizes, 3.9). Scores for the effect of near vision on difficulty with daily activities had declined (effect size, 2.43) and family relations had improved (effect size 1.90).

TABLE 4. Multivariate Analysis of Met Need Adjusted for Age, Sex, Dwelling, Education

\begin{tabular}{lcc}
\hline \multicolumn{1}{c}{ Variables } & Adjusted OR (95\% CI) & $\boldsymbol{P}$ \\
\hline Age (y) & & \\
$\quad 40-59$ & $1.0(0.4-2.2)$ & 0.97 \\
$60-69$ & $1.3(0.4-4.3)$ & 0.67 \\
$\quad 70+$ years & 1.0 & \\
Sex & $0.9(0.5-1.9)$ & 0.85 \\
$\quad$ Male & & \\
$\quad$ Female & 1.0 & \\
Location & $2.0(1.0-4.0)$ & \\
$\quad$ Rural & & \\
$\quad$ Urban & 1.0 & \\
Education & None \\
$\quad$ Primary & & \\
Secondary/University & $4.3(2.1-13.2)$ & 0.005 \\
& & \\
\hline
\end{tabular}

Willingness and Ability to Pay for Near Spectacles at Baseline and Follow-up. Three hundred twenty-three participants were interviewed regarding the amount that they would be prepared to pay for spectacles. The mean amount was 2713.3 TSh (2.17 USD; range, $0-8.00$ USD at the time of the study). Younger participants $(P=0.009)$, men $(P<0.001)$, and those from urban areas $(P<0.001)$ were willing to pay more. The overall mean proportion of the monthly family income individuals were prepared to pay was $23.7 \%$. In contrast to the absolute amounts, women and participants living in rural locations were willing to pay a significantly higher proportion of their income ( $P<0.001$ for both). At follow-up, the amount participants were willing to pay had increased to a mean of 3920 TSh (3.14 USD). Higher amounts were significantly associated with the working age group of 40 to 59 years, being male, dwelling in urban areas, and being literate (Table 7).

At baseline the majority of the 334 individuals interviewed were willing to participate in a community distribution scheme if introduced $(265 / 334,79.3 \%)$. A willingness to participate was associated with younger age groups $\left(\chi^{2}=17.8, P<0.001\right)$ and being male $\left(\chi^{2}=5.2, P=0.023\right)$, whereas those who had never worked were less willing $\left(\chi^{2}=9.1, P=0.059\right)$. All 16 village chiefs agreed to introduce and be responsible for a spectacle distribution scheme in their villages.

\section{Discussion}

This survey provides the only data on presbyopia and refractive error for Zanzibar. As anticipated, the crude prevalence of presbyopia was high but in our study, unlike others, there were no significant associations with demographic risk factors. ${ }^{7,14}$ Spectacle coverage was very low, being higher among urban dwellers and those with higher levels of education. Using WHO recommendations, the low spectacle coverage indicates that provision should be a high priority in Zanzibar.

The most commonly cited reason for not owning near spectacles was that it was not considered a priority. However, the majority agreed to participate in a community distribution scheme, if introduced. The second barrier cited was lack of money, but the mean amount participants were willing to pay for spectacles (2.17 USD) was very close to the actual cost of the spectacles provided (2.00 USD). Local private suppliers charge 12.00 to 14.00 USD per pair and the main hospitals charge 3.90 USD per pair. These prices give some explanation for the poor spectacle coverage. Those prepared to pay more were more likely to be working (i.e., younger, urban, better educated, and male). Participants were willing to pay almost a quarter of their monthly income for a pair of spectacles.

The follow-up study showed very high levels of satisfaction with near correction and highlighted the positive impact this had had on individuals' lives. The fact that only 12 individuals no longer had their spectacles at 6 months indicates that the eyeglasses were valued. The positive benefit experienced by participants was also captured in the VF and QoL question- 
TABLE 5. Mean VF Score at Baseline and at Follow-up

\begin{tabular}{|c|c|c|c|c|c|c|c|}
\hline \multirow[b]{2}{*}{ Variable } & \multicolumn{3}{|c|}{ Baseline } & \multicolumn{3}{|c|}{ Follow-up } & \multirow[b]{2}{*}{$\boldsymbol{P}$} \\
\hline & $\begin{array}{l}\text { Mean VF } \\
\text { Score }\end{array}$ & SD & $95 \% \mathrm{CI}$ & $\begin{array}{l}\text { Mean VF } \\
\text { Score }\end{array}$ & $95 \% \mathrm{CI}$ & $\begin{array}{l}\text { Effect } \\
\text { Size }\end{array}$ & \\
\hline Small print & 37.6 & 14.4 & $27.3-46.2$ & 91.7 & $86.3-97.1$ & 3.8 & $<0.001$ \\
\hline Recognizing objects & 78.1 & 8.8 & $70.0-86.2$ & 93.9 & $89.2-98.6$ & 1.8 & $<0.001$ \\
\hline Writing & 65.1 & 16.3 & $55.8-74.4$ & 93.4 & $88.5-98.3$ & 1.7 & $<0.001$ \\
\hline Cooking & 79.6 & 10.1 & $71.7-87.5$ & 96.6 & $93.1-100$ & 1.6 & $<0.001$ \\
\hline Sorting rice & 56.0 & 20.2 & $46.3-65.7$ & 92.8 & $87.7-97.9$ & 1.8 & $<0.001$ \\
\hline Threading a needle & 29.7 & 20.6 & $20.7-38.7$ & 86.0 & $79.2-92.8$ & 2.7 & $<0.001$ \\
\hline Weeding & 79.0 & 8.8 & $71.0-87.0$ & 95.0 & $90.7-99.3$ & 1.8 & $<0.001$ \\
\hline Dressing children & 79.0 & 8.0 & $71.0-87.0$ & 93.5 & $93.5-98.3$ & 1.8 & $<0.001$ \\
\hline Lighting a lamp & 80.5 & 7.4 & $72.7-88.3$ & 94.9 & $90.6-99.2$ & 1.9 & $<0.001$ \\
\hline Recognizing faces & 77.3 & 10.3 & $69.1-85.5$ & 92.0 & $86.7-97.3$ & 1.4 & $<0.001$ \\
\hline Cutting toenails & 52.8 & 18.9 & $43.0-62.6$ & 91.2 & $85.7-96.8$ & 2.0 & $<0.001$ \\
\hline Seeing mobile phone numbers & 62.5 & 16.7 & $53.0-72.0$ & 92.8 & $87.7-97.9$ & 1.8 & $<0.001$ \\
\hline
\end{tabular}

naires, which both showed large effect sizes. Further positive responses were reflected in the proportion of individuals prepared to recommend reading glasses to others with near vision difficulties and the independence the spectacles afforded them. Spectacles were used for a range of activities, and illiterate participants were just as likely to recommend near spectacles as were literate participants, and they were just as satisfied. This result is contrary to the general assumption that near spectacles are needed or valued only by the literate.

The study also highlighted that individuals were not willing to invest time and money to travel to obtain spectacles when given a prescription, which indicates that services for presbyopia must be available locally and at a low price.

Participants placed a higher monetary value on their spectacles after having experienced how useful they were, and the amount they would be willing to pay for a pair of spectacles at follow-up exceeded the cost of supplying the study spectacles (2.00 USD). This suggests that a community distribution scheme could become financially sustaining, given an appropriate pricing scheme. Zanzibar is well placed to establish PHCUs as spectacle outlets, as they are distributed widely across the island. Progress has recently been made in introducing primary eye care into PHCUs, and eye care has been included in the general medical curriculum. With further training the medical health officer or nurse could dispense near spectacles in addition to providing opportunistic detection of other ocular disease. ${ }^{19,20}$

\section{Comparisons with Other Studies}

Few population-based studies have been undertaken to estimate the prevalence of presbyopia and spectacle coverage in developing countries, perhaps because it is assumed that communities with high levels of illiteracy do not have a need for near correction. A study in rural Kenya revealed a similar prevalence of $85.4 \%$ and a lower presbyopic spectacle coverage of $6.3 \%{ }^{21}$ Studies in rural Tanzania documented a prevalence of $61.7 \%$ in individuals older than 40 years and the lower-than-anticipated prevalence was attributed to testing outdoors in sunny conditions, with pupil miosis giving increased depth of focus. ${ }^{7}$ In our study in Zanzibar, attempts were made to reduce measurement error by maintaining standard indoor lighting levels of at least 480 lux. $^{22}$ A population based assessment of presbyopia in South India recorded a lower prevalence of $55.3 \%$, but that study also included the 30 to 39-year age group. ${ }^{6}$

Recent data produced by WHO indicate that in African countries the prevalence of distance VI due to uncorrected refractive errors is $1.13 \%$ for individuals 40 to 49 years of age and $5.9 \%$ for individuals older than 50 years. ${ }^{2}$ However, these data were derived from only three population-based surveys. ${ }^{2}$ In our study the prevalence of VI due to uncorrected refractive errors was higher at $\mathbf{1 2 . 3 \%}$. The crude prevalence of refractive error was extremely high at $31.4 \% ; 95.8 \%$ being attributed to myopia. Although not investigated, much of the prevalence may have been due to index myopia.

In a study of refractive error and presbyopia in East Timor, different definitions were used for spectacle coverage and unmet need, making comparisons difficult. ${ }^{23}$ However, spectacle coverage was higher at $26.2 \%$. In East Timor $30 \%$ of the participants were prepared to pay 3.00 USD for a pair of spectacles and $43.3 \%$ were unwilling to pay as much as 1.00

TABLE 6. Mean QoL Scores at Baseline and Follow-up

\begin{tabular}{|c|c|c|c|c|c|c|c|}
\hline \multirow[b]{2}{*}{ Variable } & \multicolumn{3}{|c|}{ Baseline } & \multicolumn{3}{|c|}{ Follow-up } & \multirow[b]{2}{*}{$\boldsymbol{P}$} \\
\hline & $\begin{array}{c}\text { Mean QOL } \\
\text { Score }\end{array}$ & SD & $95 \% \mathrm{CI}$ & $\begin{array}{l}\text { Mean QOL } \\
\text { Score }\end{array}$ & $95 \% \mathrm{CI}$ & $\begin{array}{l}\text { Effect } \\
\text { Size }\end{array}$ & \\
\hline Distance vision & 68.8 & 13.1 & $66.8-70.0$ & 83.9 & $81.8-86.2$ & 1.15 & $<0.001$ \\
\hline Near vision & 44.9 & 11.8 & $43.2-46.7$ & 90.9 & $88.7-93.1$ & 3.90 & $<0.001$ \\
\hline Daily tasks & 77.0 & 9.8 & $75.6-78.5$ & 90.2 & $88.6-90.2$ & 1.35 & $<0.001$ \\
\hline \multicolumn{8}{|c|}{ Contribution of near vision } \\
\hline to difficulty & 48.3 & 15.2 & $48.3-50.5$ & 11.3 & $9.2-13.3$ & -2.43 & $<0.001$ \\
\hline General health & 70.0 & 11.3 & $68.3-71.7$ & 86.5 & $84.5-88.4$ & 1.46 & $<0.001$ \\
\hline Family relations & 82.0 & 7.2 & $81.1-83.2$ & 95.7 & $94.2-97.1$ & 1.90 & $<0.001$ \\
\hline Level of confidence & 71.6 & 15.2 & $69.3-73.9$ & 91.9 & $90.4-93.5$ & 1.34 & $<0.001$ \\
\hline
\end{tabular}


Table 7. Willingness to Pay for Near Spectacles in Mean Absolute Amounts According to Baseline Characteristics

\begin{tabular}{|c|c|c|c|c|}
\hline Variable & $n$ & $\begin{array}{l}\text { Mean Amount } \\
\text { (TSh)* }\end{array}$ & Range (TSh)* & Significance \\
\hline \multicolumn{5}{|l|}{ Age (y) } \\
\hline $40-59$ & 114 & 3969.3 & $0-15,000$ & \multirow{3}{*}{$\begin{array}{l}F=3.74 \\
2 d f \\
P=0.0258\end{array}$} \\
\hline $60-69$ & 47 & 3068.0 & $0-10,000$ & \\
\hline $70+$ & 15 & 2739.9 & $0-6,000$ & \\
\hline \multicolumn{5}{|l|}{ Sex } \\
\hline Male & 71 & 4029.6 & $0-15,000$ & \multirow{2}{*}{$\begin{array}{l}t \text {-Test } \\
P<0.001\end{array}$} \\
\hline Female & 105 & 3349.5 & $0-12,000$ & \\
\hline \multicolumn{5}{|l|}{ Dwelling } \\
\hline Urban & 84 & 4013.1 & $0-15,000$ & \multirow{2}{*}{$\begin{array}{l}t \text {-Test } \\
P<0.001\end{array}$} \\
\hline Rural & 92 & 3268.5 & $0-10,000$ & \\
\hline \multicolumn{5}{|l|}{ Literacy } \\
\hline Literate & 28 & 4250.0 & $0-10,000$ & \multirow{2}{*}{$\begin{array}{l}t \text {-Test } \\
P<0.001\end{array}$} \\
\hline Illiterate & 148 & 3505.4 & $0-15,000$ & \\
\hline \multicolumn{5}{|l|}{ Occupation } \\
\hline Never worked & 13 & 1892.2 & $0-5,000$ & \multirow{6}{*}{$\begin{array}{l}F=1.98 \\
4 d f \\
P=0.0999\end{array}$} \\
\hline Housewife & 21 & 3666.7 & $0-10,000$ & \\
\hline Nonmanual & 25 & 3800.0 & $0-10,000$ & \\
\hline Manual & 113 & 3779.6 & $0-15,000$ & \\
\hline Retired & 4 & 3524.8 & $99-6,000$ & \\
\hline Total & 176 & 3920.2 & $0-15,000$ & \\
\hline
\end{tabular}

$1250 \mathrm{TSh}=1 \mathrm{USD}$

USD. ${ }^{23}$ Demographic differences between this study and the Zanzibar study also hamper comparison.

\section{Limitations of the Study}

The major limitations relate to difficulties in recruiting individuals aged 40 to 50 years which limited our ability to analyze this age group that would have been interesting, as they are on the cusp of presbyopia. The study used WHO's proposed definition of presbyopia (inability to read N8 at $40 \mathrm{~cm}$ ), which fails to account for an individual's habitual working distance. Unfortunately, only the near addition required was recorded for this study, not the actual habitual working distance values, which were generally found to be closer than $40 \mathrm{~cm}$. Using this distance to define presbyopia would have increased the prevalence and the power of the near add needed. These findings suggest that more research is needed to define presbyopia for use in epidemiologic research. None of the participants had a detailed ophthalmic examination, and differences between presenting and best corrected distance and near VAs do not take account of ocular comorbidity. Although attempts were made to limit responder bias during the interviews, the participants were aware that they might receive presbyopic spectacles that could have influenced their responses at baseline. The VF questions were all near-related and had very positive responses, and that could have had a leading effect on the QoL questions that followed, resulting in an overestimation in mean QoL scores.

Incorporating presbyopia into the $\mathrm{RAAB}$ methodology provides a model for future RAAB surveys. The RAAB and presbyopia teams worked at a similar pace, and so participant flow was not restricted and no extra time was needed. The additional investigations, staff, and cost can be justified on account of the additional information gained. However, care must be used in selecting which clusters should be included in the presbyopia component of an RAAB, to avoid selection bias.

Increasing the availability of affordable spectacles is paramount in developing eye care services in Zanzibar. There are plans, as part of the National Prevention of Blindness program, to introduce primary eye care into the PHCUs, which will provide an opportunity for presbyopic spectacle distribution. ${ }^{24}$ Further research is needed to assess the feasibility, acceptability, and sustainability of such an initiative, including an evaluation of assessment of tiered payment with cross subsidies and assessment of the wider community benefits.

\section{Acknowledgments}

The authors thank Sarah Polack, Sheha Ramadhan, and Rajab Hilal for assisting in field work and training and Amy Taylor and Brendan Dineen for assisting in data analysis.

\section{References}

1. Resnikoff S, Pascollini D, Etya'ale D, et al. Global data on Visual impairment in the year 2002. Bull World Health Org. 2004;82: $844-851$

2. Resnikoff S, Pascolini D, Silvio P, et al. Global magnitude of visual impairment caused by uncorrected refractive errors in 2004. Bull World Health Org. 2008;86:63-70.

3. World Health Organization, Geneva. VISION2020-the Right to Sight: Global Initiative for the Elimination of Avoidable Blindness-Action Plans for 2006-2011. Geneva, Switzerland: WHO; 2007.

4. Holden B, Fricke T, May Ho S, et al. Global vision impairment due to uncorrected presbyopia. Arch Opbthalmol. 2008;126:731-739.

5. Miranda MN. The geographic factor in the onset of presbyopia. Trans Am Opbthalmol Soc. 1979;77:603-621.

6. Nirmalan P, Krishnaiah S, Shamanna B, et al. A population-based assessment of presbyopia in the state of Andhra Pradesh, South India: The Andhra Pradesh eye disease study. Invest Ophthalmol Vis Sci. 2006;47:2324-2328.

7. Burke A, Patel I, Munoz B, et al. Population-based study of Presbyopia in Rural Tanzania. Am J Ophthalmol. 2006 113:723727

8. Prevention of Blindness and Deafness. Elimination of avoidable visual disability due to refractive errors: report of an informal planning meeting. Geneva, 3-5 July 2000. Geneva: WHO; 2001: 8-9. (WHO/PBL/00.79). Available at :http://whqlibdoc.who.int/ hq/2000/WHO_PBL_00.79.pdf. Accessed July 2007.

9. Pyramid power: An innovative approach to selling spectacles to the very poorest. The Economist. January 11, 2007. Available from: 
http://economist.com/business/displaystory.cfm?story_id=8525617. Accessed January 2007.

10. Levin D. Scojo Foundation provides affordable eyeglasses to the poorest countries. The New York Times. July 23, 2007. Available at http://www.nytimes.com/2007/07/23/business/worldbusiness/ 23iht-scojo.4.6792917.html. Accessed July 2007.

11. Rao GN. An infrastructure model for the implementation of VISION2020: the right to sight. Can J Ophthalmol. 2004;39(6): 589-90.

12. Mathenge W, Kuper H, Limburg $\mathrm{H}$, et al. Rapid assessment of avoidable blindness in Nakuru district, Kenya. Ophthalmology. 2007; 114:599-605.

13. Wadud Z, Kuper H, Polack S, et al. Rapid assessment of avoidable blindness and needs assessment of cataract surgical services in Satkhira District, Bangladesh. Br J Ophthalmol. 2006;90:12251229.

14. Patel I, Munoz B, Burke A, et al. Impact of presbyopia on quality of life in a rural African setting. Am J Ophthalmology. 2006;113;(5): $728-734$.

15. Bourne RA, Dineen BP, Noorul Huq DM, et al. Correction of refractive error in the adult population of Bangladesh: meeting the unmet need. Invest Ophthalmol Vis Sci. 2004;45:410417 .

16. Bennett AG, Rabbits RB. Accommodation and near vision: the inadequate-stimulus myopias. Clinical Visual Optics. London: Butterworths; 1984;135-164.
17. Shah SP, Jadoon Z, Dineen B, et al. Refractive Errors in the adult Pakistani population: The National Blindness and Visual Impairment Survey. Ophthalmic Epidemiol. 2008;15:183-190.

18. Taylor A, Shah SP, Gilbert CE, et al. and the Pakistan National Eye Survey Study Group. Visual function and quality of life among visually impaired and cataract operated adults: the Pakistan National Blindness and Visual Impairment Survey. Ophthalmic Epidemiol. 2008;15:242-249.

19. Gajiwala U, Shah P, Desai L, et al. Training of grassroots workers from the community eye health $(\mathrm{CEH})$ programme in Southern Gujarat. Community Eye Health J. 2005;18:70-77.

20. Janowitz B, Chege J, Thompson A, et al. Community-based distribution in Tanzania: cost impacts of alternative strategies to improve worker performance. Int Family Planning Perspect. 2000; 26(4):158-160, 193-195.

21. Sherwin JC, Keeffe JE, Kuper, H, et al. Functional presbyopia in a rural Kenyan population: the unmet presbyopic need. Clin Exp Ophthalmol. 2008;36:245-251.

22. Borish IM. Borish's Clinical Refraction. Philadelphia: WB Saunders; 1998;98-100.

23. Ramke J, Du Toit R, Palagyi A, et al. Correction of refractive error and presbyopia in Timor-Leste. Br J Ophthalmol. 2007;91:869-866.

24. Zanzibar Health Sector Reform Strategic Plan (II) 2006-2007. Revolutionary Government of Zanzibar: Ministry of Health and Social Welfare; 2006. 